\title{
Intra-uterine transmission of paratuberculosis (Johne's disease) in farmed red deer
}

\author{
HCJ van Kooten ${ }^{*}$, CG Mackintosh ${ }^{\dagger \S}$ and AP Koets*
}

\begin{abstract}
AIM: To determine whether intra-uterine transmission of paratuberculosis (Johne's disease) occurs in farmed red deer (Cervus elaphus) in New Zealand.

METHODS: On four different farms, nine late-stage pregnant hinds with Johne's disease were slaughtered and samples were taken from them and their 10 fetuses. Samples of the hepatic, ileocaecal and mesenteric lymph nodes and the posterior ileum were collected from the hinds. The lung, liver, spleen, jejunum and ileum from the fetuses were sampled, as were the placentomes. Blood samples were tested using the 'Paralisa' test, a modified immunoglobulin $\mathrm{G}_{1}$ ( $\left.\mathrm{IgG}_{1}\right)$ enzyme-linked immunosorbent assay (ELISA). Tissue samples were cultured using the BACTEC system, and fixed samples were sectioned and histological slides examined.

RESULTS: All nine hinds and 9/10 fetuses (one hind had twins) were culture-positive for Mycobacterium avium subsp paratuberculosis $(M . p t b)$. Six hinds had gross lesions of Johne's disease, while all hinds had characteristic histopathological lesions affecting the ileum, ileocaecal valve and associated lymph nodes. The only histopathological change observed in the fetuses was some mild inflammation in the lungs of one individual. Acid fast organisms (AFOs) were seen in histological sections of the lymph nodes and ileum of six hinds, and none were seen in tissues from the fetuses. These six hinds were Paralisa-positive, whereas the remaining hinds and fetuses were serologically-negative.
\end{abstract}

CONCLUSIONS: These results confirm that there is a high risk of transmission of $M$. $p t b$ from clinically affected hinds to their fetuses during pregnancy.

CLINICAL RELEVANCE: Johne's disease is an increasingly important disease responsible for deaths in young red deer. Recognising the influence of intra-uterine transmission on the spread of this disease may be an important step towards improved control of Johne's disease.

KEY WORDS: Paratuberculosis, Johne's disease, Mycobacterium paratuberculosis, farmed red deer, intra-uterine transmission

\section{Introduction}

Paratuberculosis, or Johne's disease, caused by Mycobacterium avium subsp paratuberculosis $(M . p t b)$, is a chronic intestinal disease of ruminants. It is characterised clinically by diarrhoea and weight loss in cattle and deer, whereas the main clinical sign in sheep is weight loss. In contrast to cattle and sheep, in which clinical signs usually first appear in adult animals, Johne's disease also affects young red deer (Mackintosh et al 2004b). On deer farms, disease in animals aged $8-15$ months is an increasingly important cause of economic loss (Mackintosh et al 2004ab).

Both horizontal transmission, via environmental contamination, and vertical transmission of paratuberculosis have been described in cattle and sheep. Previous research has shown that intra-uterine transmission occurs in cattle and sheep, both in clinical and subclinical cases (Pearson and McClelland 1955; Lawrence 1956; Doyle 1958; Kopecky et al 1967; McQueen and Russell 1979; Seitz et al 1989; Sweeney et al 1992). Transmission of infection in deer is assumed to have both horizontal and vertical components (Mackintosh et al 2004b), and intra-uterine transmission has been demonstrated in two pregnant red deer hinds with Johne's disease in Austria (Deutz et al 2003).

Although clinical signs of Johne's disease are not often seen in adult female hinds on deer farms (Mackintosh et al 2004b), significant numbers may be subclinically infected. Intra-uterine transmission could be important in the epidemiology of the disease and may contribute to outbreaks in young deer. Understanding the risks of intra-uterine transmission may assist in developing ways of reducing the number or severity of outbreaks in young deer. As there is currently no Johne's disease vaccine licensed for use in deer (Mackintosh et al 2004ab), controlling the disease through management and test-and-cull procedures, based on a sound understanding of the epidemiology, may be a practicable solution. The aim of this study was to determine whether intrauterine transmission of $M$. $p t b$ occurs in farmed red deer in New Zealand.

\section{Materials and methods}

\section{Selection of animals}

In October 2004, nine adult red deer hinds, from four farms in South Canterbury, New Zealand, ranging from 2 to $10+$ years of age, that showed clinical signs of Johne's disease, were isolated from their herds and euthanised on the farm. All hinds had lost weight and had intermittent diarrhoea. They were all in the last

$\begin{array}{ll}\text { AFO } & \text { Acid fast organism } \\ \text { ELISA } & \text { Enzyme-linked immunosorbent assay } \\ \mathrm{H} \& \mathrm{E} & \text { Haematoxylin and eosin } \\ \mathrm{IgG}_{1} & \text { Immunoglobulin } \mathrm{G}_{1} \\ M \cdot p t b & \text { Mycobacterium avium subsp paratuberculosis } \\ \mathrm{ZN} & \text { Ziehl-Neelsen }\end{array}$

\footnotetext{
Department of Farm Animal Health and Department of Infectious Diseases and Immunology, Faculty of Veterinary Medicine, University of Utrecht, Yalelaan 1, De Uithof, 3584 CL Utrecht, Netherlands.

$\dagger$ AgResearch Invermay, PO Box 50034, Mosgiel, New Zealand.

$\$$ Author for correspondence. Email: colin.mackintosh@agresearch.co.nz
} 
trimester of pregnancy and the fetal age was estimated using mating information acquired from the farmers. The crown-to-rump length of each fetus was also measured (Table 1).

\section{Collection of tissues}

During post mortem, great care was taken to prevent cross-contamination between tissue samples from the hind and the fetus. Clean gloves and sets of sterilised instruments were used for each individual hind and fetus. One operator performed the necropsy of each hind and excised the uterus before taking any tissue samples. A second operator opened the uterus and collected samples from the placenta and the fetus.

At necropsy, the internal organs from the hinds and fetuses were examined for the presence of lesions and abnormalities. A selection of tissues was taken from each hind and fetus $(n=10$; there was one set of twins), based on the approach of an Austrian study (Deutz et al 2003). From the hinds, fresh samples of the hepatic, ileocaecal and mesenteric (upper jejunum and lower ileum) lymph nodes were taken, and transported on ice to AgResearch Wallaceville for culture, and samples of the ileocaecal and mesenteric lymph nodes, ileocaecal valve and lower ileum were fixed in $10 \%$ buffered formalin for histopathological examination. Blood samples were collected in plain vacutainer tubes from the hinds by jugular venepuncture, and submitted for serological testing.

Random samples from a placentome were collected for histopathology. From each fetus, fresh samples of lung, ileum and jejunum were taken for culture, and samples of lung, liver, spleen, jejunum and ileum were fixed, as described above, for histopathological examination. Blood samples were taken in a plain vacutainer tube directly from the heart of each fetus for serological testing.

\section{Processing of tissues \\ Culture}

The fresh samples collected from the hinds and their fetuses were subjected to BACTEC culture using a modification of the method described by Whittington et al (1999). Briefly, homogenised tissues were decontaminated with $0.75 \%$ cetylpyridinium chloride for $40 \mathrm{~min}$, centrifuged and then inoculated into supplemented BACTEC vials and incubated at $37^{\circ} \mathrm{C}$. Once a week the vials were examined for the presence of bacterial growth. Vials with positive growth indices were examined for the presence of $M$. $p t b$, using a Mycobactin-dependence test and a polymerase chain reaction test for the presence of IS900.

\section{Serology}

Sera were examined using the Paralisa test, an ELISA specific for $\mathrm{IgG}_{1}$, described by O'Brien et al (2004), which was conducted at the Disease Research Laboratory, University of Otago, Dunedin, New Zealand.

\section{Histopathology}

The fixed samples were processed routinely and sections were stained with Ziehl-Neelsen $(\mathrm{ZN})$ and haematoxylin and eosin (H\&E). ZN-stained sections were examined under high power for the presence of AFOs, and H\&E slides were examined to assess the severity of lesions characteristic of Johne's disease, which were graded using the scale presented in Table 2. This scale could not be used for grading fetal tissues, because neither AFOs nor granulomas were seen.

\section{Results}

Four hinds (D, E, F and I) had obvious gross lesions characteristic of Johne's disease in red deer, including enlarged mesenteric lymph nodes, thickened ileum and posterior jejunum, and prominent lacteal ducts. Histopathological examination of sections of ileum, ileocaecal valve and associated lymph nodes showed that three hinds (C, G and H) had mild, two (A and D) had moderate and four (B, E, F and I) had severe microscopic lesions typical of Johne's disease, and grades of lesion severity varied from 2 to 11 (Table 3). The six deer with the most severe lesions all had AFOs in sections of intestine and lymph nodes.

The fetuses were estimated to be from 150 to 218 days gestation (Table 1). One of the fetuses (Fetus b) appeared to have died in utero some time before necropsy and was semi-mummified. None of the other fetuses had any gross signs of disease. Histopathological examination of fetal tissues revealed some minor inflammatory lesions only in the lung of Fetus $\mathrm{g}$.

All samples of hepatic and mesenteric lymph nodes from the nine hinds were culture-positive, and 9/10 fetuses were culture-positive from at least one tissue (Table 3). Seven (70\%) lung and intestinal samples were culture-positive; five fetuses were positive for both tissues and four were positive for one tissue. One (10\%) fetus was culture-negative for both lung and intestinal samples, although its mother was culture-positive and had moderate (Grade 6) lesions. Both twins were culture-positive (Table 3).

Table 1. Individual information about nine red deer hinds and their fetuses, from four farms in South Canterbury, New Zealand.

\begin{tabular}{|c|c|c|c|c|c|}
\hline Hind & Farm & Age of hind (years) & Fetus & Fetal age $^{\mathrm{a}}$ (days) & CR length (cm) \\
\hline A & 1 & 8 & a & 201 & 61 \\
\hline$B$ & 2 & 3 & $b$ & $180-200$ & 35 \\
\hline C & 2 & $>4$ & C & $180-200$ & 53 \\
\hline D & 2 & 2 & $d$ & $150-170$ & 44 \\
\hline E & 3 & 4 & e & 218 & 69 \\
\hline \multirow[t]{2}{*}{$\mathrm{F}$} & 3 & 4 & $f 1$ & 209 & 52 \\
\hline & & & f2 & 209 & 49 \\
\hline G & 3 & $>10$ & $g$ & 209 & 55 \\
\hline $\mathrm{H}$ & 3 & $>10$ & $\mathrm{~h}$ & 209 & 44 \\
\hline 1 & 4 & 10 & $\mathrm{i}$ & 210 & 45 \\
\hline
\end{tabular}

a Fetal age estimated from mating information 
Table 2. Grading system used to describe the severity of Johne's disease in samples from nine red deer hinds, based on the most severe histopathological lesions seen in the intestinal and lymph node tissues for each animal.

\section{Grade Pathological lesion(s)}

$0 \quad$ No lesions seen

1 Occasional Langhan's-type giant cell seen or scattered macrophages in villi and no acid fast organisms (AFOs) seen

2 Occasional granuloma within a section of small intestine or lymph node only seen within one area of the intestine (e.g. posterior jejunum) and no AFOs seen

3 Occasional granuloma within small intestine or lymph nodes and no AFOs seen

$4 \quad$ Occasional granuloma within small intestine or lymph nodes plus AFOs seen

5 Occasional to scattered islands of granulomas within small intestine or lymph nodes and Grade $1^{\text {a }}$ villi plus AFOs seen

6 Scattered islands of granulomas within small intestine or lymph nodes and Grade 2 villi plus AFOs seen

7 Scattered islands of granulomas within small intestine or lymph nodes and Grade 3 villi plus AFOs seen

8 Scattered islands of granulomas within small intestine or lymph nodes, submucosal lesions and Grade 3 villi plus AFOs seen

9 Large areas of granulomatous lesions in intestine or lymph node, submucosal lesions and Grade 3 villi plus AFOs seen

10 Scattered areas of granulomatous lesions in intestine or lymph node, submucosal lesions, Grade 3 villi and mesenteric/pericapsular lymph node granulomas plus AFOs seen

11 Large areas of granulomatous lesions in intestine or lymph node, submucosal lesions, Grade 3 villi and mesenteric/pericapsular lymph node granulomas plus AFOs seen

a Grade 1 villi = mild bluntening and fusion of villi; Grade 2 villi = moderate bluntening and fusion of villi; Grade 3 villi $=$ marked bluntening and fusion of villi

The six hinds that were Paralisa-positive had the most severe lesions (Grades 6-11), while the three hinds that were Paralisanegative had less severe lesions (Grades 2-3). All the sera from the fetuses were Paralisa-negative. No microscopic abnormalities were detected in sections of placentomes.

The time it took for cultures to become positive in the BACTEC system was also correlated with the severity of the lesions and the presence of AFOs. Cultures from the most severely affected hinds were first detected as positive in 8-15 days, whereas cultures from mildly affected hinds took 29-50 days to become positive (Table 3). A decrease in the grade of lesion severity of one unit corresponded to an approximately 3-day delay in being able to distinguish significant growth in the BACTEC system. Fetal tissues took 36-42 days to become positive.

\section{Discussion}

This study demonstrated intra-uterine transmission of paratuberculosis occurred in pregnant red deer, and 8/9 hinds had infected fetuses. Johne's disease was confirmed in all the hinds, using a combination of clinical signs, gross pathology, histopathology, serology and culture. Although no AFOs or microscopic lesions of paratuberculosis were seen in sections of fetal tissues, infection was confirmed by culture in 9/10 fetuses. Great care was taken to avoid cross-contamination between each hind and its fetus and between hinds, and therefore it is unlikely that any of the positive cultures were due to contaminated samples. These findings are similar to those of Deutz et al (2003), who demonstrated intra-uterine transmission of paratuberculosis in two red deer hinds from a game park in Austria. In their study, two clinically affected, pregnant red deer were killed and sampled and $M$. $p t b$ was isolated from both hinds and their fetuses.

This study suggests that culture is a more sensitive test for determining the infection status of the hind and the fetus than histopathological examination and serology, a similar finding to that of Schroen et al (2003, non-peer-reviewed). It was shown by Reddacliff et al (2003) that the time to detect growth of $M$. ptb in BACTEC was inversely correlated with the number of organisms in the inoculum. In our study, there was a positive association be- tween the rate of growth of $M$. $p t b$ (i.e. the inverse of the number of days before cultures were detected as positive) in the BACTEC system and the severity of lesions seen in sections of intestine from which the inoculum was taken. There were large numbers of AFOs visible in the severe lesions, whereas there were no visible AFOs in the sections that had the mildest lesions. The long culture period for the samples from fetuses and hinds with negative histopathology suggests that there were few organisms present. The Paralisa test uses three antigens, avian and Johnin tuberculins, and a protoplasmic antigen made from $M$. $p t b$ (O'Brien et al 2004, non-peer-reviewed). Preliminary data indicated a sensitivity value of around $90 \%$ in a selection of red deer from infected farms. In our study, the Paralisa test was positive in 6/9 hinds and in none of the 10 fetuses. Negative serology in the fetuses was expected because their immune system was immature and antibody production is usually associated with increasingly severe disease. The latter was demonstrated in the hinds, which were only Paralisa-positive when the severity of lesions was Grade 6 or greater. On this severity scale, values of $\leq 4$ indicated there were no visible AFOs, whereas $\geq 5$ had increasing numbers of AFOs and a more florid host response.

The fetus that was negative in all the tests came from the youngest hind, which was in the earliest stage of gestation, although the hind had Grade 6 lesions. This may indicate that infection of the fetus takes place in the later stages of gestation, or that if the fetus was infected the number of organisms present was below the sensitivity threshold of the tests at this stage.

The crown-to-rump length was measured for every fetus at necropsy, in order to estimate fetal age. However, the correlation between crown-to-rump length and an estimate of fetal age based on mating information appeared to be poor. It has been documented that the equation that is used to calculate the length of gestation using the crown-to-rump length is only reliable between 24 to 59 days of gestation (Revol and Wilson 1990). After that, differences in fetal growth make the outcome unpredictable. Also, the growth of the fetus may have been affected by Johne's disease in the hind.

The finding of twins in one of the hinds was unexpected, because naturally mated red deer seldom give birth to twins. This afforded us the opportunity to see if there was any difference in 
Table 3. Results of Paralisa test, culture and histopathology for samples from nine red deer hinds and their ten fetuses. The time it took to first detect a positive culture in BACTEC from tissues from hinds and fetuses is recorded in days. The results of histopathology for tissues from the hinds are recorded as presence of acid fast organisms (AFOs) and lesion severity grade. The Paralisa test and histopathology results were negative for all fetuses.

\begin{tabular}{|c|c|c|c|c|c|c|c|c|c|c|}
\hline \multirow[b]{3}{*}{ ID } & \multicolumn{6}{|c|}{ Hind } & \multicolumn{4}{|c|}{ Fetus } \\
\hline & \multirow[b]{2}{*}{ Sample } & \multirow[b]{2}{*}{ Paralisa } & \multicolumn{2}{|c|}{ Culture } & \multicolumn{2}{|c|}{ Histology } & \multirow[b]{2}{*}{$I^{a}$} & \multirow[b]{2}{*}{ Sample } & \multicolumn{2}{|c|}{ Culture } \\
\hline & & & Result & Days to +ve & AFOs & Grade & & & Result & Days to $+v e$ \\
\hline \multirow[t]{4}{*}{ A } & Blood & Pos & & & & 7 & a & Lung & Pos & 43 \\
\hline & MLN & & Pos & 8 & Pos & & & Ileum/Jej & Neg & - \\
\hline & HLN & & Pos & 8 & & & & & & \\
\hline & Ileum/Jej & & & & Pos & & & & & \\
\hline \multirow[t]{4}{*}{ B } & Blood & Pos & & & & 9 & $b$ & Lung & $\mathrm{Neg}$ & - \\
\hline & MLN & & Pos & 15 & Pos & & & Ileum/Jej & Pos & 36 \\
\hline & HLN & & Pos & 8 & & & & & & \\
\hline & Ileum/Jej & & & & Pos & & & & & \\
\hline \multirow[t]{4}{*}{ C } & Blood & Neg & & & & 3 & c & Lung & Neg & - \\
\hline & MLN & & Pos & 42 & Neg & & & Ileum/Jej & Pos & 43 \\
\hline & HLN & & Pos & 50 & & & & & & \\
\hline & Ileum/Jej & & & & Neg & & & & & \\
\hline \multirow[t]{4}{*}{ D } & Blood & Pos & & & & 6 & $d$ & Lung & Neg & - \\
\hline & MLN & & Pos & 8 & Pos & & & Ileum/Jej & Neg & - \\
\hline & HLN & & Pos & 8 & & & & & & \\
\hline & Ileum/Jej & & & & Pos & & & & & \\
\hline \multirow[t]{4}{*}{$E$} & Blood & Pos & & & & 11 & e & Lung & Pos & 36 \\
\hline & MLN & & Pos & 8 & Pos & & & Ileum/Jej & Pos & 42 \\
\hline & HLN & & Pos & 15 & & & & & & \\
\hline & Ileum/Jej & & & & Pos & & & & & \\
\hline \multirow[t]{6}{*}{$\mathrm{F}$} & Blood & Pos & & & & 11 & $\mathrm{f} 1$ & Lung & Pos & 34 \\
\hline & MLN & & Pos & 8 & Pos & & & Ileum/Jej & Pos & 36 \\
\hline & HLN & & Pos & 8 & & & & & & \\
\hline & Ileum/Jej & & & & Pos & & & & & \\
\hline & & & & & & & f2 & Lung & Pos & 42 \\
\hline & & & & & & & & Ileum/Jej & Neg & - \\
\hline \multirow[t]{4}{*}{$\mathrm{G}$} & Blood & Neg & & & & 2 & g & Lung & Pos & 34 \\
\hline & MLN & & Pos & 29 & Neg & & & Ileum/Jej & Pos & 42 \\
\hline & HLN & & Pos & 29 & & & & & & \\
\hline & Ileum/Jej & & & & Neg & & & & & \\
\hline \multirow[t]{4}{*}{$\mathrm{H}$} & Blood & Neg & & & & 3 & $\mathrm{~h}$ & Lung & Pos & 42 \\
\hline & MLN & & Pos & 29 & Neg & & & lleum/Jej & Pos & 42 \\
\hline & HLN & & Pos & 34 & & & & & & \\
\hline & Ileum/Jej & & & & $\mathrm{Neg}$ & & & & & \\
\hline \multirow[t]{4}{*}{ I } & Blood & Pos & & & & 10 & $\mathrm{i}$ & Lung & Pos & 42 \\
\hline & MLN & & Pos & 8 & Pos & & & Ileum/Jej & Pos & 36 \\
\hline & HLN & & Pos & 13 & & & & & & \\
\hline & Ileum/Jej & & & & Pos & & & & & \\
\hline
\end{tabular}

$a_{f 1}$ and $f 2$ were twin fetuses from Hind $F$

ID = identity; +ve = positive; Pos = positive; $M L N=$ mesenteric lymph node; Jej = jejunum; Neg = negative; HLN = hepatic lymph node

infection status between the twins. Twin red deer fetuses usually share placental circulation, so if infection spreads from the dam to the fetus by the haematogenous route it is likely that if one was infected they would both be infected. We found that both twins were culture-positive, although only samples from the lungs were positive in one of them. This might have been due to variation in the site of sampling in the lung or the number of organisms present. The dam was heavily infected but, surprisingly, the size of the fetuses appeared to be normal for that length of gestation.

The actual mechanism for intra-uterine transmission has not been demonstrated. The most likely theory is that macrophages carrying $M$. ptb migrate through small gaps between cells lining the placentomes, from maternal blood to the fetal blood circulation. However, this migration would require the macrophages to travel across a six-layer thick barrier between the dam and the fetus.

Production losses due to infection with $M$. $p t b$ are mainly due to the direct loss of clinically diseased animals, and associated with loss of value of carcasses when gross tuberculous-like lesions are found in mesenteric lymph nodes at slaughter in subclinically affected animals. Some farmers may be tempted to retain clinically affected hinds long enough to salvage a live fawn. The results of this study suggest that it would be inadvisable for farmers to retain such animals, because they are very likely to pass the infection on to their offspring and are probably shedding significant 
numbers of $M$. $p t b$ organisms into the environment. Intra-uterine transmission has not yet been demonstrated in subclinically infected hinds and a follow-up study is planned to investigate this possibility.

\section{Acknowledgements}

The authors would like to acknowledge the following people or groups: the farmers that provided the animals; Noel Beatson for assistance with necropsies; Dianne Sebelin, Marjorie Orr, John Gill, Gary Clark, Chunyi Li and Dawn Clark for assistance with histopathology; Geoff de Lisle and Gary Yates for the BACTEC culture; Frank Griffin and the Disease Research Laboratory for the Paralisa; Roger Littlejohn for statistical analysis; and the University of Utrecht and the Foundation for Research Science and Technology in New Zealand for funding.

\section{References}

Deutz A Von, Spergser J, Rosengarten R, Köfer J. Erstnachweis der intrauterinen Übertragung von Paratuberkulose bei Rot- und Gamswild. [First detection of intra-uterine transmission of paratuberculosis in red deer and chamois.] Zeitschrift für Jagdwissenschaft 49, 314-9, 2003

Doyle T. Foetal infection in Johne's disease. Veterinary Record 70, 238, 1958

Kopecky K, Larsen A, Merkal R. Uterine infection in bovine paratuberculosis. American Journal of Veterinary Research 28, 1034-5, 1967

Lawrence W. Congenital infection with Mycobacterium johnei in cattle. Veterinary Record 68, 312-4, 1956

Mackintosh C, Griffin F, de Lisle GW. Review of Johne's disease in deer. Proceedings of the 1st World Deer Veterinary Congress; Deer Course for Veterinarians, No. 21, Deer Branch of the New Zealand Veterinary Association. Pp 126-9, 2004 a
Mackintosh CG, de Lisle GW, Collins DM, Griffin JFT. Mycobacterial diseases of deer. New Zealand Veterinary Journal 52, 163-74, 2004 b

McQueen D, Russell E. Culture of Mycobacterium paratuberculosis from bovine foetuses. Australian Veterinary Journal 55, 203-4, 1979

O'Brien R, Rodgers C, Liggett S, Spittle E, Crosbie P, Griffin F. Immunodiagnosis of TB and Johne's disease in deer. Proceedings of the 1st World Deer Veterinary Congress; Deer Course for Veterinarians, No. 21, Deer Branch of the New Zealand Veterinary Association. Pp 102-5, 2004

Pearson J, McClelland T. Uterine infection and congenital Johne's disease in cattle. Veterinary Record 67, 615-6, 1955

Reddacliff L, Nicholls P, Vadali A, Whittington R. Use of growth indices from radiometric culture for quantification of sheep strains of Mycobacterium avium subsp. paratuberculosis. Applied and Environmental Microbiology 69, 3510-6, 2003

Revol B, Wilson P. Rectal Ultrasonographic Pregnancy Diagnosis and Foetal Ageing of Red Deer. Massey University, Palmerston North, New Zealand, 1990

Schroen C, Bradley T, McDonald W, Condron R. Diagnostic Tests for Johne's Disease in Deer. A report for the Rural Industries Research and Development Corporation, RIRDC, Publication No. 03/100, ACT, Australia, 2003

Seitz S, Heider L, Hueston W, Bech-Nielsen S, Rings M, Spangler L. Bovine fetal infection with Mycobacterium paratuberculosis. Journal of the American Veterinary Medical Association 194, 1423-6, 1989

Sweeney R, Whitlock R, Rosenberger A. Mycobacterium paratuberculosis isolated from fetuses of infected cows not manifesting signs of the disease. American Journal of Veterinary Research 53, 477-80, 1992

Whittington R, Marsh I, McAllister S, Turner M, Marshall D, Fraser C. Evaluation of modified BACTEC 12B radiometric medium and solid media for culture of Mycobacterium avium subsp. paratuberculosis from sheep. Journal of Clinical Microbiology, 1077-83, 1999

Submitted 02 May 2005

Accepted for publication 18 July 2005 